\title{
Identifying self-care behaviors in middle-aged women: A qualitative study
}

Fereshteh Ghaljaei ${ }^{1}$, Nasrin Rezaee ${ }^{1}$, Alireza Salar ${ }^{1}$

${ }^{1}$ Ph.D., Community Nursing Research Center, Zahedan University of Medical Sciences, Zahedan, Iran

Type of article: Original

\begin{abstract}
Background: Women in their middle-age enjoy abilities that affect their health promotion and improvement. Throughout their entire lifetime, women strive to maintain and improve their health through benefiting from behaviors that come from experience.

Objective: This study was carried out with the aim of identifying self-care behaviors that middle-aged women consider as far as maintaining and promoting their health are concerned.

Methods: The study was conducted using a qualitative approach in conventional content analysis. Participants comprised of 20 middle-aged women from Zahedan, Iran in 2016 that were invited to enter the study using purposive sampling, and were given semi-structured interviews. After data collection, all interviews were transcribed, reviewed and then the subcategories were extracted.

Results: The findings of this study include a main category "preventive self-care behaviors" and three subcategories of "understanding health and disease", "health knowledge" and "awareness of the health threats".

Conclusion: The findings suggest that preventive self-care behaviors of women are associated with features such as understanding health and disease, health knowledge and awareness of the associated health risks. As a matter of fact, preventive behaviors encompass strategies that women apply to improve their physical and mental health.

Keywords: Self-care, Middle-aged, Women, Qualitative study, Iran
\end{abstract}

\section{Introduction}

Women's health is affected by biological, societal, political and economic contexts which are spread like a continuous extent (continuum) during their life cycle, bearing significantly close relationship with their living conditions. Therefore, by focusing on the matters pertaining to women's health issues over their lifespan is of utmost importance (1). Results have shown that factors such as socio-cultural, gender, health beliefs and understanding health needs are involved in the formation of the preventive behaviors of women $(2,3)$. For example, in one study women viewed menopause as the freedom period (4). In addition, other results indicated that women in Iran and Turkey were trying to conceal their menopause, and they do regard menopause as the end of femininity and $(5,6)$. Middle-age marks as one of women's developmental stages in the age range 40-65 and is the longest cycle of development. This period, having its own characteristics, can be the height of a person's life, provided that health should be considered in all its dimensions (7). The World Health Organization (WHO) defined health in its broader sense in its constitution (2010) as being the most important indicator of development. The concept of health is one of the leading metaparadigms in the nursing practice, which is a health-driven discipline. Thus, one of the responsibilities of nurses is to promote public health (8). As such, if nurses wish to maintain and improve the health of the members of society, they should be able to understand their condition, which is feasible only through doing research using qualitative approach. Because this research approach, citing the words of real people in a natural and real-life setting, can impart us valuable information. In this regard, the results of a study that systematically examines the articles published in the country, showed that despite the fact that women's health is a priority for the health system, 40 percent of their health-related issues are not taken into consideration. Moreover, the majority of studies have addressed healthcare issues such as prenatal care, malnutrition and women's cancer, while women's

\section{Corresponding author:}

Dr. Nasrin Rezaee, Department of Nursing, Faculty of Nursing and Midwifery, Zahedan University of Medical Sciences, Zahedan, Iran. Tel: +98.5433442482, Fax: +98.5433442481, Email: nasrin_rezaee2005@yahoo.com Received: December 28, 2016, Accepted: September 12, 2017, Published: November 2017

iThenticate screening: July 18, 2017, English editing: November 06, 2017, Quality control: November 15, 2017

(C) 2017 The Authors. This is an open access article under the terms of the Creative Commons Attribution-NonCommercialNoDerivs License, which permits use and distribution in any medium, provided the original work is properly cited, the use is non-commercial and no modifications or adaptations are made. 
right to health goes far beyond the right to have merely access to health care systems (9). In addition to the systematic overview, qualitative studies on women's health within the country also showed that although not too many and relatively sparse studies have been conducted on their health issues, the overall results of this study, from a bird's-eye view, showed that women's self-care behaviors are not yet identified across the country, which can help us in the field of their health. While the nature of qualitative research overview suggested that for the purpose of protecting and improving women's health, efforts should be made to identify health dimensions from their own viewpoint (10). So that the findings of a qualitative study in Peru showed the lack of screening programs for breast cancer, despite the availability of facilities, from the women's viewpoint, or put differently, consumers of health services, had been due to their distrust of the medical staff (11). Also, results of a study that examined how these preventive behaviors emerge regarding breast cancer, showed that these studies helped neatly bulldoze ahead with plans for developing prevention programs for women and health authorities (12). In addition to the above, it seems that the roles women adopt in the family have a direct impact on developing preventive behaviors in women; they, at the time of their roles often overlook issues related to their health (1). Also, women at middle-age, sacrifice for their family and give priority to their problems. These can affect various aspects of their health, and one of the serious consequences of this period of self-neglect and one serious implication coming out of this cycle is self-ignoring and lack of attention to self-care behaviors, and this could compromise their health $(3,10)$. In fact, the identification of preventive self-care behaviors helps bring to light the facilitators and inhibitors affecting women's health, as viewed by women. As Cohen (1998) in his study stated that women's problems ought to be identified by themselves and according to the degree of control they have over their lives (13). And it is important that the curriculum developers understand the health needs of women in different periods of life (14). Therefore, this study aimed to identify selfcare behaviors in middle-aged women.

\section{Material and Methods}

The current study is a qualitative study using content analysis. This method is one of the approaches to qualitative research, and also includes qualitative data analysis methods. Content analysis, analysis of written messages, oral or visual, with raw data were extracted based on inference, summarized and incorporated into categories. In Conventional content analysis, categories and their names are extracted from the data (15).

\subsection{Participants and Data Collection}

In this study, participants were selected through purposive sampling. Sampling of middle-aged women with maximum variation including education level, marital status and job data was performed until data saturation. This study involved 20 middle-aged women from Zahedan, Iran in 2016. Being middle-aged (ages 40-60 years) was the selection criteria for women. The interview location, relative to the qualitative research method, was a natural setting that would enable access to middle-aged women. To this end, interviews were conducted in areas such as home or work. Collecting data was through face-to-face and semi-structured interviews. During the interview questions such as "What is your understanding of health" and "What do you do for your health during one day of your life?" were asked. To gain further information, the interview went ahead using follow-up questions such as "What do you mean by that?" or "please explain more on this?" The duration of each interview was between 30 to 45 minutes. Each participant was interviewed once, so 20 interviews were conducted.

\subsection{Data Analysis}

Data analysis was done concurrent with data collection. The transcript of the interviews was broken down into its constituent semantic and smallest meaningful units after several times of reviewing. Then the codes were re- read on the basis of semantic similarity in the subcategories and the main categories were replaced. Varieties of methods were used during the study in order to ensure the accuracy of data. Participants' modification was used. The codes that did not represent the participant's views were corrected. Moreover, the interviews text (transcript), codes and categories were revised by two faculty members who were conversant with both qualitative research and were experts in the field of women's health. Selection of participants from maximum variation sample helped increase the credibility of data.

\subsection{Consideration of Ethics}

The ethics adhered to by the researchers in the study included obtaining informed consent from participants after expressing the aim of the study, giving them the right to withdraw at any time they wish, maintaining anonymity and confidentiality of data and presenting the results to the participants if requested. 


\section{Results}

The findings showed that preventive self-care behaviors encompassed "understanding of health and disease", "health knowledge" and "awareness of health threats" (Table1). In fact, preventive self-care behaviors in women emerge in association with features such as understanding health and disease, health knowledge and awareness of the associated health risks.

Table 1. The extracted category and sub-categories

\begin{tabular}{|l|l|l|}
\hline Category & Sub-Categories & Guiding Codes \\
\hline $\begin{array}{l}\text { Providing preventive self-care } \\
\text { behaviors }\end{array}$ & $\begin{array}{l}\text { Understanding health and } \\
\text { disease }\end{array}$ & $\begin{array}{l}\text { Individual's perception of physical and mental } \\
\text { health }\end{array}$ \\
\cline { 2 - 3 } & Health knowledge & $\begin{array}{l}\text { Individual's perception of disease } \\
\text { activity status }\end{array}$ \\
\cline { 2 - 3 } & Awatient neglect in healthcare \\
\cline { 2 - 3 } & Awareness of health threats & awareness of health and disease \\
\hline
\end{tabular}

\subsection{Understanding health and disease}

Understanding their health and disease, led the women to behaviors that had an important role in maintaining and improving their health. Women had a different understanding of their health, but all of them alluded to physical and mental health and the relationship between these two dimensions. As to the understanding of health and disease, one participant said: "... physical health may happen due to aging, deterioration of joints and arthritis, but mental health is more important, I sometimes feel pain in the hands, feet and my shoulder. After consulting a doctor I was told there was no reason. But the pain rooted in the stressful issues that I suffered. When the stress disappeared, I was relieved of my physical pain..." (Participant1). Another participant stated: "minor diseases like blood pressure and blood sugar and blood lipids that are for everyone in this age, I would not consider these as diseases, I believe that if these factors will not be taken as a disease anymore if brought under control to some extent. What is important for good health is to have peace and tranquility, this is very good, and it means good health ... "(Participant10).

\subsection{Health knowledge}

Emergence of "preventive self-care behaviors" women depend on their knowledge of health, diet, physical activity and even their neglect of their health status. Here are some quotes from participants about their health knowledge in dealing with health problems. "... Stress is an important cause of constipation in me. I realized this when drinking laxative could not help me out with my problem, after a few years I realized that whenever I am stressed, constipation comes in. Since having realized this, I tried not to stress out or control it. In fact, by having this knowledge, I try to keep constipation at bay" (Participant 1). On the behaviors generated as a result of their knowledge about health, another participant said: "The higher the level of functional literacy, the clients mostly complain about psychological rather than physical problems. One literate 40-year old lady as compared to one illiterate 40-year old lady has different reasons for their referral. The literate woman has sleep disorders (insomnia); the illiterate one ushers in mostly with physical problems. This unschooled or poorly educated lady might be suffering from insomnia as well, but she does not recognize it as a serious case to consult a doctor. She might have been in the grip of insomnia over the last year, while the educated lady may visit the doctor three to four days after the emergence of the problem. The undereducated mostly refer with physical problems" (Participant 10). As to the preventive care behavior relating to the nutritional status, one participant says: "... I take awfully good care as far as food issues are concerned. I do not eat fatty foods at nights, feeding more on bread, cheese and walnuts. I do feed on chicken and white meat prepared and cooked by poaching or steaming ... "(Participant 9). On ignoring health status, another participant said:" I do not give too much care to healthy diet, like not eating fat foods. Generally speaking, I am not on diet-friendly recipes. For instance, despite the fact that my mom has diabetes and I am at substantially higher risk of developing diabetes, I always mull over taking more care about my diet, but I do not stick to it, I indulge in cookies-" (Participant 12).

\subsection{Awareness of health risks}

An awareness of the threats of physical and mental health had positive impact on preventive self-care behaviors of the women participants in this study. In addition, women believed that many of their health problems were due to aging and entering middle-age period. The following are some quotes from middle-aged women, especially their being aware of their health status. "... This is quite clear to me that year after year my health deteriorates. From age 30 onwards I think my health has changed compared to the past, my physical, mental status and my memory are not 
like before. I feel withering every year in myself ... " (Participant 16). On the issue of the health status awareness, being a genetic disposition, another participant said, "Blood fat runs in our family, it is almost about 20 years since I started consuming lipid-regulating pills, I myself do try to be on a diet." (Participant 10).

\section{Discussion}

The results of the current study indicate that preventive self-care behaviors include a set of behaviors which middleaged women get engaged in towards maintaining and enhancing their psychophysical health relying on a thorough understanding of good health and illness, health knowledge and being aware of the health risks. Understanding good health and illness may affect diverse facets of physical, psychological and social health. Findings in some studies tell of understanding good health and illness, or the challenges stemming from an understanding of contracting diabetes or breast cancer. Women's understanding of their diseases has impacted their physical, psychological and social dimensions $(16,17)$; whereas in the present study, understanding health and disease has occurred under conditions in which women did not have serious psychophysical problems. The participants in this research expressed their understanding of health and disease using sentences such as health means proper functioning of the body systems, health means prevention, and mental health takes precedence over physical health. Undoubtedly, their understanding of health and illness, using such descriptions, when encountering psychophysical problems, can help them out to take steps towards maintaining their health by embarking on more effective strategies. Herein the findings of a research on the experiences gained by women with cancer showed that the understanding of death by the women under study had been mere death and annihilation, having been affecting their self-care behaviors (18). Also, difficulty in changing the eating habits was the theme of another study on the women's understanding of weight loss. In another research, women's understanding of good health was beauty and white skin, the consequences of strategies applied by these women had endangered their health $(19,20)$. However, the results showed that an individual's understanding of health and disease can lead to behaviors which play a role in their health (1). Given the fact that the women of the current study were not suffering from any physical problem affecting their lifestyle, what was clear in their utterances was that the living conditions affected their understanding of health and disease in a manner that those women with lower levels of education paid more heed to the aspect of physical health, while other aspects remained unknown to them; whereas the women with higher education levels cared about physical, psychological and social health as well. Health knowledge is another subcategory of the present study. Controlling behaviors, are referred to in one study, as behaviors caused by the cancer infected women's self-care. In the aforementioned study, women's dysfunctional behaviors emerged as a result of their insufficient knowledge about the risks associated with cancer (21). Another research finding, which addressed the practice of physical activities in women with diabetes, showed that their preventive self-care behaviors in terms of physical activity were contingent upon their behavioral, normative and controlling behaviors (22). The studies suggest that such preventive and easygoing behaviors that women show off under self-care behaviors relate to the time when they are grappling with physical problems $(10,23)$. On the other hand, women's awareness of the disease type will lead to their initiating self-care behaviors. In a study conducted on working women taking on exercise in self-care behaviors, they viewed physical exercise as one component of self-caring. The results of which, showed that views change in the aftermath of awareness, followed by action (23). Moreover, in a research study in which the human subjects were Brazilian women, although cancer screening programs for, say, Pap Smear, are being carried out routinely in gynecology centers in Brazil, the preventive self-care plans will not be developed as long as women are not well-informed in biomedics (24). Another research finding with women participants from East Asia (Chinese and Korean), showed that women's lack of knowledge about the benefits of sunlight led to vitamin D deficiency in them (19). However, preventive self-care behaviors in women depend significantly on developing behaviors such as understanding health and disease, gaining knowledge on health and being aware of health threats in them. It should be mentioned that a setting in which a woman lives, plays a pivotal role in shaping preventive self-care behaviors. The participants of the present study were engaged in numerous commitments and have their own limitations to be interviewed.

\section{Conclusions}

Characteristics such as understanding health and disease, health knowledge and awareness of threats to health, play a role in the emergence of self-care behaviors. As a matter of fact, the findings of the study showed that the behavior of middle-aged women towards health promotion, depends on individual aspects; of course, we should not ignore the fact that the context of where a woman was raised or currently lives has been central to the shaping of these behaviors. This behavior has on offer. So, it looks whatever plan is offered to maintain and improve the health of women, the women themselves should have a basic role in regulating the plan. 
http://www.ephysician.ir

\section{Acknowledgments:}

This article was supported by Zahedan University of Medical Sciences with research ID: ir.zaums.rec.1395.20

\section{Conflict of Interest:}

There is no conflict of interest to be declared.

\section{Authors' contributions:}

All authors contributed to this project and article equally. All authors read and approved the final manuscript.

\section{References:}

1) Rezaee N, Seyedfatemi N, Salar A, Ghaljaei F. Identifying Health Seeking Behaviors among Middle-aged Women: A Qualitative Study. J Mazandaran Univ Med Sci. 2016; 26(140): 175-86.

2) Majaj L, Nassar M, De Allegri M. "It's not easy to acknowledge that I'm ill": a qualitative investigation into the health seeking behavior of rural Palestinian women. BMC Womens Health. 2013; 13: 26 . doi: 10.1186/1472-6874-13-26. PMID: 23705933, PMCID: PMC3679862.

3) Salsali M, Rezaee N, Seyedfatemi N, Rahnavard Z. Perception of Iranian Middle-Aged Women Regarding Moral Health Concept: A Content Analysis. Glob J Health Sci. 2015; 7(3): 267-73. doi: 10.5539/gjhs.v7n3p267. PMID: 25948455, PMCID: PMC4802150.

4) Morrison LA, Brown DE, Sievert LL, Reza A, Rahberg N, Mills P, et al. Voices from the Hilo Women's Health Study: talking story about menopause. Health Care Women Int. 2014; 35(5): 529-48. doi: 10.1080/07399332.2013.829067. PMID: 24134306, PMCID: PMC3925469.

5) Jamshidi Manesh M, Jouybary L, Peyrovi H, Sanagoo A. The ups and downs of sex life in menopausal stage: a qualitative study. Qom University of Medical Sciences Journal. 2009; 3(2): 1-6.

6) Ayranci U, Orsal O, Orsal O, Arslan G, Emeksiz DF. Menopause status and attitudes in a Turkish midlife female population: an epidemiological study. BMC Women's Health. 2010; 10: 1. doi: 10.1186/1472-6874$10-1$.

7) Heidari F, Mohammad Khan Kermanshahi S, Vanaki Z, Kazem Nejad A. A Survey the effect of planned program of health promotion on stress management in middle-aged women. Iranian Journal of Nursing Research. 2011; 6(22): 16-23.

8) Meleis A. Theoretical Nursing: Development\& Progress. 4ed. Lippincott William\& Wilkins; 2007.

9) Vedadhir AA, Sadati H, Ahmadi B. A content analysis of Iranians scientific and academic health journals. Women in Development and Politics. 2008; 6(2): 133-55.

10) Seyedfatemi N, Salsali M, Rezaee N, Rahnavard Z. Women's Health Concept: A Meta-Synthesis Study. Iranian J Publ Health. 2014; 43(10): 1335-44. PMID: 26060695, PMCID: PMC4441886.

11) Hayes Constant TK, Winkler JL, Bishop A, Taboada Palomino LG. Perilous Uncertainty: Situating Women's Breast-Health Seeking in Northern Peru. Qual Health Res. 2014; 24(6): 811-23. doi: 10.1177/1049732314529476. PMID: 24747287.

12) Khazaee-Pool M, Montazeri A, Majlessi F, Rahimi Foroushani A, Nedjat S, Shojaeizadeh D. Breast cancer-preventive behaviors: exploring Iranian women's experiences. BMC Women's Health. 2014; 14(1): 41. doi: 10.1186/1472-6874-14-41. PMID: 24606758, PMCID: PMC3973958.

13) Cohen M. Towards a framework for women's health. Patient Education and Counseling. 1998; 33: 187-96. doi: 1016/S0738-3991(98)000.

14) Paluck EC, Allerdings M, Kealy K, Dorgan H. Health promotion needs of women living in rural areas: an exploratory study. Can J Rural Med. 2006; 11(2): 111-6. PMID: 16630437.

15) Elo S, Kyngas H. The qualitative content analysis process. Journal of Advanced Nursing. 2008; 62(1): $107-$ 15. doi: 10.1111/j.1365-2648.2007.04569.x.

16) Valizadeh S, Agamohamadi M, Mohammadi E, Abrahimi H. Health according to the experinces of Iranian women with diabeties: A phenomenologyical study. Journal of nursing and midwifery Uromia University of medical sciences. 2010; 10(3): 0-0.

17) Fasihi Harandy T, Anoosheh M, Ghofranipour F, Montazeri A, Ahmadi F, Mohammadi E, et al. Healthrelated quality of life in Iranian breast cancer survivors: a qualita $\neg$ tive study. Payesh. 2012; 11(1): 73-81.

18) Gurm BK, Stephan J, Mackenzie G, Doll R, Barroetavena MC, Cadell S. Understanding Canadian Punjabispeaking South Asian woman's experience of breast cancer: A qualitative study. Int J Nurs Stud. 2008; 45(2): 266-76. doi: 10.1016/j.ijnurstu.2006.08.023. 
19) Jang H, Koo FK, Ke L, Clemson L, Cant R, Fraser DR, et al. Culture and sun exposure in immigrant East Asian women living in Australia. Women Health. 2013; 53(5): 504-18. doi: 10.1080/03630242.2013.806386. PMID: 23879460.

20) Hammarström A, Wiklund AF, Lindahl B, Larsson C, Ahlgren C. Experiences of barriers and facilitators to weight-loss in a diet intervention a qualitative study of women in northern Sweden. BMC Women's Health. 2014; 14: 59. doi: 10.1186/1472-6874-14-59. PMID: 24739099, PMCID: PMC3998240.

21) Lamyian M, Heidarnia AR, Ahmadi F, Faghihzadeh S, AguilarVafaie M. Women's prospect of breast cancer early detection behavior: a qualitative research. Journal of Birjand University of Medical Sciences. 2008; 15(3): 88-102.

22) Ghazanfari Z, Niknami S, Ghofranipour F, Larijani B. Regular physical activity from perspective of females with diabetes: A qualitative study. The Horizon of Medical Sciences. 2009; 15(1): 5-14.

23) Vahedian Shahroodi M, Amin-Shokravi F, Haidarnia A, Jabbari Nooghabi H. A Survey on the Effects of the Pender's Health Promotion Model on Prediction of the Employees' Physical Activity. Health Education \& Health Promotion (HEHP). 2013; 1(1): 51-66.

24) Rico AM, Iriart JA. Where there's a woman, there's a Pap smear: the meanings assigned to cervical cancer prevention among women in Salvador, Bahia State, Brazil. Cad Saude Publica. 2013; 29(9): 1763-73. doi: 10.1590/S0102-311X2013001300016. PMID: 24068222. 